Article

\title{
In BPS1 Downregulated Roots, the BYPASS1 Signal Disrupts the Induction of Cortical Cell Divisions in Bean-Rhizobium Symbiosis
}

\author{
Manoj-Kumar Arthikala ${ }^{1,+}$, Kalpana Nanjareddy ${ }^{1, *, \dagger}$ and Miguel Lara ${ }^{2, *}$ \\ 1 Ciencias Agrogenómicas, Escuela Nacional de Estudios Superiores Unidad León-Universidad Nacional \\ Autónoma de México (UNAM), León C.P. 37684, Mexico; manojarthik@gmail.com \\ 2 Instituto de Biología, Universidad Nacional Autónoma de México, Ciudad Universitaria, Coyoacan, \\ Ciudad de México C.P. 04510, Mexico \\ * Correspondence: kalpana.ccg@gmail.com (K.N.); mlara@unam.mx (M.L.); Tel.: +52-555-623-0252 (M.L.) \\ + These authors contributed equally to this work.
}

Received: 1 November 2017; Accepted: 27 December 2017; Published: 3 January 2018

\begin{abstract}
BYPASS1 (BPS1), which is a well-conserved gene in plants, is required for normal root and shoot development. In the absence of BPS1 gene function, Arabidopsis overproduces a mobile signalling compound (the BPS1 signal) in roots, and this transmissible signal arrests shoot growth and causes abnormal root development. In addition to the shoot and root meristem activities, the legumes also possess transient meristematic activity in root cortical cells during Rhizobium symbiosis. We explored the role of Phaseolus vulgaris BPS1 during nodule primordium development using an RNA-interference (RNAi) silencing approach. Our results show that upon Rhizobium infection, the PvBPS1-RNAi transgenic roots failed to induce cortical cell divisions without affecting the rhizobia-induced root hair curling and infection thread formation. The transcript accumulation of early nodulin genes, cell cyclins, and cyclin-dependent kinase genes was affected in RNAi lines. Interestingly, the PvBPS1-RNAi root nodule phenotype was partially rescued by exogenous application of fluridone, a carotenoid biosynthesis inhibitor, which was used because the carotenoids are precursors of BPS1 signalling molecules. Furthermore, we show that the PvBPS1 promoter was active in the nodule primordia. Together, our data show that PvBPS1 plays a vital role in the induction of meristematic activity in root cortical cells and in the establishment of nodule primordia during Phaseolus-Rhizobium symbiosis.
\end{abstract}

Keywords: BYPASS1 gene; carotenoid biosynthesis; common bean; cortical cell divisions; infection thread; legume root nodule; Rhizobium

\section{Introduction}

The most important class of plant pigments, carotenoids, are abundant isoprenoid-derived molecules that are mainly $\mathrm{C}_{40}$ tetraterpenoids with a series of double bonds [1,2]. Carotenoid biosynthesis occurs in the plastids, where carotenoids are incorporated into the light-harvesting and photosynthetic reaction centre complexes. In these complexes, carotenoids serve to both absorb light energy and dissipate excess energy (photo-protection) [3-5]. Carotenoids can also be processed by carotenoid cleavage dioxygenases (CCDs) to form apocarotenoids, which function as hormones, flavours, and pigments, and serve as mobile signalling molecules [6-9].

Mobile signalling molecules are crucial to coordinate responses throughout the plant to maintain normal development. Auxins and cytokinins have been widely studied as classical long-distance signalling molecules in various aspects of plant development [10-13]. In this context, CCD7 and CCD8 are shown to be associated with the synthesis of the hormone strigolactone (SLs), a root-derived signal that 
inhibits shoot branching [14-17]. Strigolactones are known to be synthesized in plant roots that are colonized by arbuscular mycorrhizal (AM) fungi [7]. The roots synthesize these apocarotenoids during AM fungi symbiosis, and they are similar to those that are synthesized during carotenoid metabolism. Recent studies have shown that SLs are also found to be involved in the establishment of root nodule symbiosis in the formation of both indeterminate and determinate nodules in legumes [18-21].

Similar to SLs, BYPASS1 (BPS1), a putative long-distance signal, was uncovered by analysis of the Arabidopsis BPS1 mutant. The BPS1 protein functions as a negative regulator, which is required to prevent excess production of the mobile signalling molecule. BPS genes are present as a family of three genes in Arabidopsis, all of which contribute to negative regulation of the BPS signal [22]. The seedlings of BPS1 mutants constitutively produce a signal that results in failure to properly establish pro-vascular tissue, shoot and root developmental defects, and poor apical meristem activity [22]. Chimeric shoot grafting experiments in Arabidopsis proved that BPS1 is a root-derived signal [23,24]. This novel signalling molecule was found to require normal carotenoid biosynthesis for its synthesis, which is conserved in plant lineages. When BPS1 mutants are grown in media containing carotenoid biosynthesis inhibitors, such as fluridone or 2(4-chlorophenylthio)-triethylaminehydrochloride (CPTA), they become albinos due to photobleaching. However, the BPS1 mutant phenotype of arrested root and shoot growth was partially recovered [23] when treated with inhibitors. Further analysis revealed that the BPS signal was not related to abscisic acid or SLs [25].

Based on a partial chemical characterization assay, Adhikari and associates [26] found that the BPS mobile molecule is a metabolite and that in BPS1 mutants, shoot and root development is affected due to cell cycle arrest in the $G_{1}$ phase in apical meristems. In legumes, along with the shoot and root meristem activities, transient meristematic activity occurs in root cortical cells after rhizobia infection during nodule symbiosis. Unlike other carotenoid biosynthesis pathway derived molecules abscisic acid and SLs, the role of BPS mobile signal in symbiosis is still enigmatic [27]. Root nodule symbiosis involves the development of specialized organs, called nodules, to house the symbiont, Rhizobium. The development of nodules requires the dedifferentiation of cortical cells at the site of infection in response to the rhizobial infection threads. Since Arabidopsis BPS1 mutants were found to be defective in meristematic cell divisions, we hypothesized a putative role of BPS1 in the root nodule development of legumes. To test our hypothesis, we selected Phaseolus vulgaris BPS1 and silenced their transcripts in the hairy root system of $P$. vulgaris and analysed the nodule phenotype. We found that in PvBPS1 downregulated roots, the BPS1 signal disrupts the induction of cortical cell divisions in bean-Rhizobium symbiosis.

\section{Materials and Methods}

\subsection{Plant Growth and Rhizobium Inoculation}

Seeds of the common bean (P. vulgaris L.) cultivar Negro Jamapa were surface sterilized and germinated in the dark for two days [28]. The two-day-old seedlings were transferred to pots with sterile vermiculite, inoculated with freshly cultured Rhizobium tropici (strain CIAT899) at an $\mathrm{OD}_{600}$ of 0.05, and irrigated with Broughton \& Dilworth (B \& D) [29] medium without nitrate.

\subsection{Sequence Identification, Alignment and Phylogenetic Analysis}

Arabidopsis BPS1 protein sequences AT1G01550.1 and AT1G01550.2 were used to retrieve the BPS1 sequences of Lotus japonicus, Medicago truncatula, Glycine max, and P. vulgaris by sequence-based homology search using BLASTP search from the genome databases L. japonicus gene expression atlas V2 (https:/ /ligea.noble.org/v2/) and Phytozome v12.1 (http:/ /www.phytozome.net). The presence of Bypass1/DUF793 domain (PF05633) in identified sequences was verified in the Pfam database (http: // pfam.xfam.org/) using the HMMER 3.0 program (Chevy Chase, MD, USA; http://hmmer.org/). The structures of BPS genes were analysed using the Gene Structure Display Server (http://gsds.cbi. pku.edu.cn/). 
To generate the alignment of the twelve BPS1 proteins and Arabidopsis BPS2 and BPS3 proteins, multiple sequence alignment was performed using the T-Coffee program [30], and alignment output was generated using Boxshade version 3.21 (Köln, Germany; http:/ / sourceforge.net/projects / boxshade/). The analyses of protein domains and conserved motifs were conducted using Pfam (http: //www.sanger.ac.uk/software/pfam/search.html) and Multiple Em for Motif Elicitation (MEME) software [31], respectively. Phylogenetic analyses of the BPS1 proteins that are based on amino acid sequences were carried out using the Neighbour-Joining (NJ) methods in MEGA 7 [32]. NJ analyses were performed using $p$-distance methods, pairwise deletion of gaps, and the default assumptions that the substitution patterns among lineages and substitution rates among sites were homogeneous. Support for each node was tested with 1000 bootstrap replicates. Branches with bootstrap values of less than $80 \%$ were collapsed to simplify tree structures.

\subsection{Plasmid Construction and Composite Plants}

To generate the BYPASS1 promoter: $\beta$-glucuronidase (GUS) construct, a 1154-bp fragment of PvBPS1.1 and 1124 bp of PvBPS1.2 promoters that were upstream of the translation initiation codons were identified and isolated from P. vulgaris genomic DNA, according to Nanjareddy et al. [33]. The PCR fragments were cloned separately into the pENTR/D-TOPO vector (Thermo Fisher Scientific, Waltham, MA, USA) and recombined into the destination binary vector pBGWSF7.0 [34] according to the manufacturer's instructions (Thermo Fisher Scientific, Waltham, MA, USA). To create the PvBPS1-RNAi construct, a fragment corresponding to the $3^{\prime}$-coding region of PvBPS1 was amplified from cDNA from $P$. vulgaris root tips using specific oligonucleotides (Table S1). The PCR product was cloned into the pTdT-DC-RNAi vector [35] using the Gateway system (Thermo Fisher Scientific, Waltham, MA, USA). The resulting RNA-interference (RNAi) construct drives the transcription of a hairpin loop PvBPS1-RNAi under control of the $35 S$ promoter. The pTDT-DC-RNAi vector also harbours the NOSpro:tdT cassette, which mediates the hairy root expression of the molecular fluorescent marker tdTomato [36] and allows for the identification of transformed roots. The empty pTdT-DC-RNAi vector was used as the control. The correct orientations of the above clones were confirmed by sequencing the plasmid insert. The recombinant plasmids were introduced into Agrobacterium rhizogenes strain K599, and then transformed into P. vulgaris roots using the rapid hairy root transformation method, as described recently by Nanjareddy and associates [33].

\subsection{Physiological Analysis}

Composite plants grown in pots containing sterile vermiculite were used for root growth parameters and leaf area measurement experiments. The composite plants were irrigated daily with B \& D nutrient medium and maintained under growth chamber conditions with a 16-h photoperiod and $65 \%$ relative humidity at $27 \pm 1{ }^{\circ} \mathrm{C}$. Transgenic roots expressing red fluorescent protein were selected from individual plants at 10 days post-transplantation, and root growth parameters, such as root length and the lateral root density, were obtained. Lateral root density was calculated using the following formula: $D=L R / L^{\prime}$, where $D=$ density of lateral roots; $L R=$ number of lateral roots; and, $L^{\prime}=$ length of the main root between the first and the last lateral root [37]. Shoot parameters, such as shoot fresh weight and leaf area, were obtained from the individual PvBPS1-RNA $i$ and control composite plants. The total leaf area was calculated using the Easy Leaf Area method, as described by Easlon and Bloom [38]. Composite plants grown in 15-cm glass tubes containing nutrient medium were used to observe the root hair morphology.

\subsection{Expression Analysis}

Transcript levels were quantified using quantitative real-time PCR (RT-qPCR). The total RNA was isolated from frozen root tissues using the Plant total RNA Kit, according to the manufacturer's recommendations (Sigma-Aldrich, St. Louis, MO, USA). To eliminate genomic DNA contamination, the RNA samples were incubated with RNase-free DNase $\left(1 \mathrm{U} \cdot \mu \mathrm{L}^{-1}\right)$ at $37^{\circ} \mathrm{C}$ for $15 \mathrm{~min}$ and then 
at $65{ }^{\circ} \mathrm{C}$ for $10 \mathrm{~min}$. The RNA integrity and concentration were determined by electrophoresis and a Nanodrop ND-2000 spectrophotometer (Thermo Fisher Scientifics, Waltham, MA, USA), respectively. Quantitative real-time PCR was performed using the iScript ${ }^{\mathrm{TM}}$ One-Step RT-PCR Kit with SYBR ${ }^{\circledR}$ Green and an iQ5 Multicolor Real-time PCR Detection System, according to the manufacturer's instructions (Bio-Rad, Hercules, CA, USA). Each reaction contained 40 ng of RNA as template. A control sample lacking a reverse transcriptase enzyme was included to confirm the absence of contaminant DNA. Relative expression values were calculated using the $2^{-\Delta \mathrm{Ct}}$ method, where the quantification cycle $(\mathrm{Cq})$ value equals the $\mathrm{Cq}$ value of the gene of interest minus the $\mathrm{Cq}$ value of the reference gene [39]. The P. vulgaris reference genes EF1 $\alpha$ and IDE were used as internal controls [40]. The relative expression values were normalized with respect to the expression levels of these two reference genes, which were calculated according to a previously described method [41]. The reported values are the averages of three biological replicates, and each sample was assessed in triplicate. The expression levels of genes listed in Table S1 were quantified using gene-specific oligonucleotides.

\subsection{Fluridone Treatment}

The carotenoid biosynthesis inhibitor fluridone (Sigma, St. Louis, MO, USA) was applied to the roots of wild-type plants or composite plants (control and PvBPS1-RNAi). The wild-type plants were treated with different concentrations of fluridone $(5,10,50,100$, and $200 \mu \mathrm{M})$ daily for up to ten days, and observations were taken for plant mortality. The R. tropici-GUS inoculated transgenic roots of composite plants were treated with $100 \mu \mathrm{M}$ fluridone for seven days, and observations were recorded for dividing cortical cells and nodule primordia. These plants were maintained under growth chamber conditions with a 16-h photoperiod and $65 \%$ relative humidity at $27 \pm 1{ }^{\circ} \mathrm{C}$.

\subsection{Microscopy}

To analyse the rhizobial infection phenotype, control and PvBPS1-RNAi transgenic roots inoculated with $R$. tropici-GUS were harvested at different time points and stained for GUS activity according to Jefferson [42]. The GUS stained roots were clarified using $0.5 \%$ sodium hypochlorite for $8 \mathrm{~h}$, and then examined for nodule symbiosis phenotype viz., infection threads (ITs), cortical cell divisions, nodule primordia, and nodules under a light microscope (Leica, DMLB bright-field microscope, Buffalo Grove, IL, USA). GUS-stained 18-day-old nodules were sectioned using a razor blade. The sections were mounted in 10\% glycerol and observed under a light microscope. The GUS-stained transgenic roots expressing PvBPS1.1 or PvBPS1.2 promoters were observed under a stereo microscope (Leica), and images of nodule primordia and mature nodules were obtained. To observe the root hair morphology, uninoculated or $R$. tropici-inoculated roots were removed from the glass tubes, and the root segments were quickly mounted on microscopic slides with mounting buffer $(50 \mathrm{mM}$ sodium phosphate buffer $\mathrm{pH} 7.0$ in $40 \%$ glycerol). The images were obtained uniformly from the root elongation zones under a light microscope.

\section{Results}

\subsection{The BPS1 Gene Has Multiple Members}

Based on Arabidopsis BPS1 sequences (AT1G01550.1 and AT1G01550.2), the legume protein sequences were obtained from Phytozome v12.1 (https:/ / phytozome.jgi.doe.gov/pz/portal.html) and L. japonicus gene expression atlas V2 (https://ligea.noble.org/v2/). A total of 12 gene sequences were obtained from Arabidopsis and legumes: two genes in Arabidopsis, five genes in G. max (Glyma.10G104200.1, Glyma.09G255800.1, Glyma.07G066500.1, Glyma.18G129300.1, and Glyma.18G237000.1), two genes each in M. truncatula (Medtr8g028710.3 and Medtr7g078700.5) and P. vulgaris (Phvul.008G059500.1 and Phvul.008G059600.1), and one in L. japonicus (Lj1g3v2752330.1). The homologues of BPS1 were named PvBPS1.1, PvBPS1.2, etc. The predicted open reading frame coding sequences encode proteins with 184, 353, 355, 305, 351, 353, 353, 358, 353, and 347 amino 
acids, respectively. In Arabidopsis, both BPS1 homologues had 349 aa. To understand the relationship between the Arabidopsis BPS gene family (BPS1, BPS2, and BPS3) and legume BPS1 homologues, all BPS genes from Arabidopsis were used for domain structure analysis. Domain analysis of the BPS genes using Pfam revealed the presence of one or two DUF793 domains (PF05633; Figure S2) in all the BPS1 homologues, similar to Arabidopsis BPS1 genes. However, Arabidopsis BPS2, Glyma.10G104200.1 (184 aa), and Glyma.18G129300.1 did not have this domain. BPS3 had a DUF241 domain. The presence of DUF793 domains in Phaseolus BPS1 homologues confirmed that they were homologues of the Arabidopsis BPS1 gene. Furthermore, gene structural analysis showed a highly conserved feature of a single intron in the $5^{\prime}$ untranslated region (UTR) in most of the BPS genes (Figure S3).

Conserved motif analysis showed a total of six conserved motifs in BPS1 protein sequences. The motif distribution was similar in all of the BPS1 homologues that contained DUF793 domains. BPS1 homologues of G.max, Glyma.10G104200.1, Glyma.18G129300.1, and Lj1g3v2752330.1 did not show all of the motifs that were found in BPS1 homologues containing the DUF793 domain. Further, the motif analysis showed that all the homologues of Phaseolus, Medicago and Arabidopsis had the same motif arrangement in a similar order (Figure S4).

Next, phylogenetic analysis of the BPS1 sequences was carried out to understand the phylogenetic relationship among the selected legumes. The results that were obtained using the Neighbour-Joining method in MEGA 7 showed three main groups. Lj BPS1 and Medtr7g078700.5 were in the first group; Phaseolus and G. max (Glyma.09G255800.1 \& Glyma.18G237000.1) formed the second group. The third group had one branch with Arabidopsis BPS family genes alone (Figure 1A).

\subsection{Phaseolus vulgaris BPS1 Express during Root Nodule Symbiosis}

The genome of P. vulgaris has two copies of the PvBPS1 gene, PvBPS1.1 and PvBPS1.2. In pairwise alignment, the PvBPS1.1 amino acid sequence shared $83.5 \%$ of its identity with PvBPS1.2 (Table S2). To understand the expression profiles of PvBPS1.1 and PvBPS1.2, we evaluated the transcript accumulation of vegetative and reproductive organs of wild-type bean plants by quantitative RT-PCR. Transcripts of both PvBPS1 genes were detected in all of the tested tissues (viz., root, shoot, leaf, flower, and young pod); however, high expression was seen in flower tissues. Among the PvBPS1 genes, the transcript accumulation of PvBPS1.2 was found to be significantly higher in leaf and flower tissues when compared to PvBPS1.1 (Figure 1B). Next, we measured the expression of PvBPS1 under Rhizobium tropici symbiotic conditions. In Rhizobium-infected root tissues, the accumulation of both copies of PvBPS1 transcripts significantly increased in the early stages, i.e., during infection thread formation and cortical cell divisions ( 3 and $5 \mathrm{dpi}$ ), during nodule primordia formation $(7 \mathrm{dpi})$ and detached nodules $14 \mathrm{dpi}$, when compared to the uninoculated ( $0 \mathrm{dpi})$ root tissues (Figure 1C). However, in 21-day-old detached nodules, the promoter expression was found to be induced only in PvBPS1.1. Among the PvBPS1 genes, a slight but not significant difference was observed in the transcript levels between PvBPS1.1 and PvBPS1.2 under Rhizobium symbiotic condition. Together, these results suggest that PvBPS1.1 and PvBPS1.2 are expressed in various organs of the common bean plant and that their expression increases under $P$. vulgaris- $R$. tropici symbiotic conditions.

We next examined the spatiotemporal activity of PvBPS1.1 or PvBPS1.2 promoter-driven GUS expression during nodulation. P. vulgaris hairy roots expressing pPvBPS1.1::GUS or pPvBPS1.2::GUS were inoculated with wild-type $R$. tropici, and the nodulated roots were assayed at different time points to detect GUS activity. PvBPS1.1 promoter was active in roots and in nodule primordium at $7 \mathrm{dpi}$ (Figure 2A); similarly, the PvBPS1.2 promoter was found to be active in nodule primordium and in root vasculature (Figure 2C). However, in mature nodules, both PvBPS1 promoters were expressed at similar levels in nodules and in root vascular tissues (Figure 2B,D). The promoter activity was also detected in central tissues of nodules expressing PvBPS1.1 or PvBPS1.2 promoter-GUSA fusions (Figure 2E,F). These results show that both PvBPS1.1 and PvBPS1.2 promoters are expressed in nodule primordia and in mature nodules of $P$. vulgaris. 
A
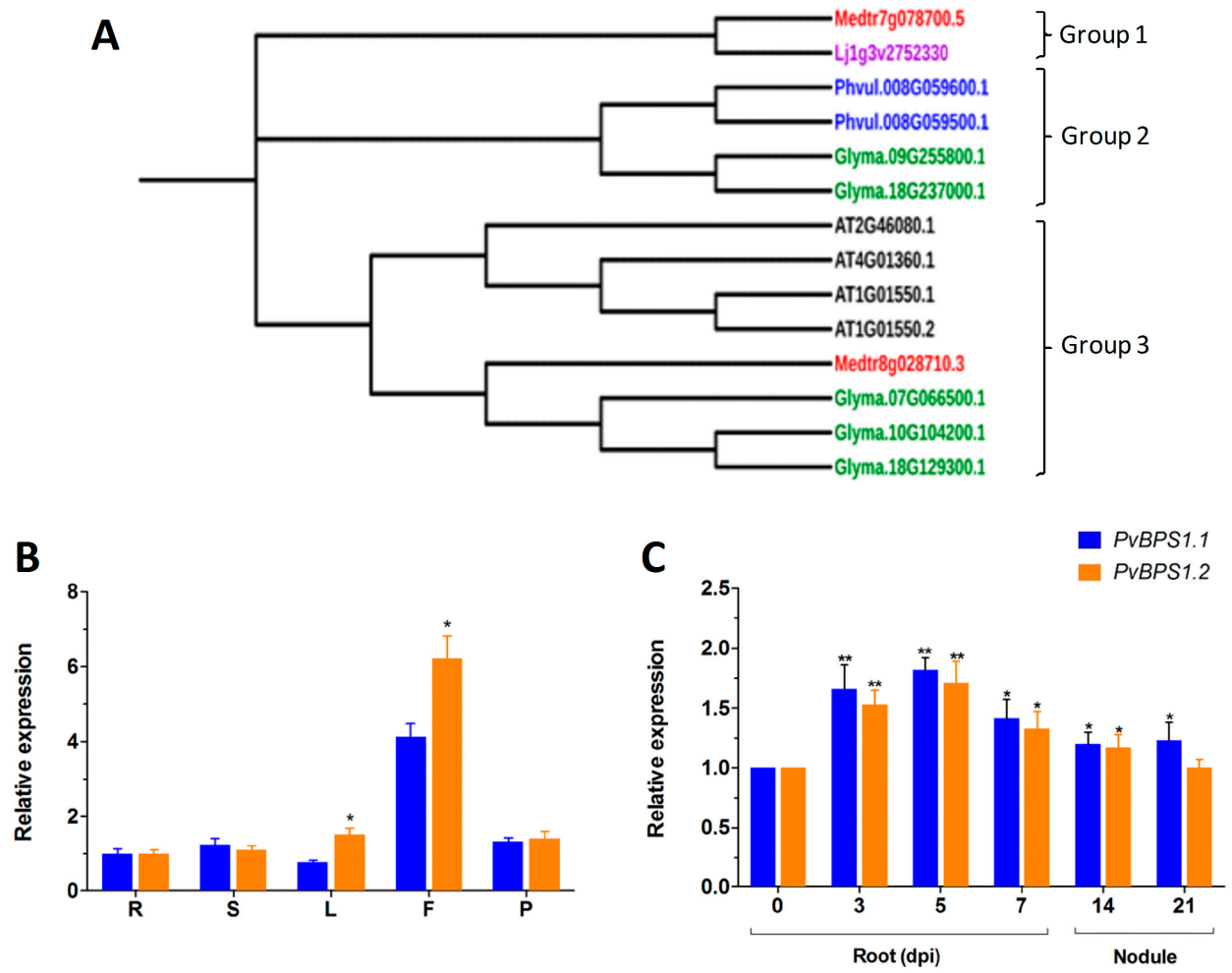

Figure 1. Phylogenetic analysis and expression patterns of BPS(BYPASS)1-related genes in wild-type Phaseolus vulgaris tissues. (A) Protein homologues of BPS1 in Glycine max, P. vulgaris, Medicago truncatula, Lotus japonicus and BPS1 (AT1G01550.1 and AT1G01550.2), BPS2 (AT4G01360.1), and BPS3 (AT2G46080.1) of Arabidopsis thaliana were constructed using the neighbour-joining (NJ) method with MEGA 7. The phylogenetic tree shows three major groups. Accession numbers are shown in the phylogenetic tree. Bootstrap values are indicated against each branch with 1000 replications. Quantitative real-time PCR (RT-qPCR) analysis of PvBPS1.1 (Phvul.008G059500) and PvBPS1.2 (Phvul.008G059600) expression in different vegetative and reproductive tissues (B), uninoculated $0,3,5,7$, dpi roots, 14- and 21-day-old nodules (C). The data are presented as the averages of three biological replicates $(n>9)$, and error bars indicate the means \pm standard error of the mean (SEM). The statistical significance of differences between PvBPS1.1 and PvBPS1.2 was determined using an unpaired two-tailed Student's $t$-test $\left({ }^{*} p<0.05 ;{ }^{* *} p<0.01\right)$. dpi, days post inoculation with Rhizobium tropici; R, root; S, stem; L, leaf; F, flower; P, young pod.

\subsection{Silencing of PvBPS1 Transcripts Affects Shoot and Root Growth}

There are two BPS1 genes in the genome of Phaseolus, and they share $86 \% 3^{\prime}$ UTR sequence identity. To silence these BPS1 genes, a PvBPS1-RNAi construct was designed to target a $3^{\prime}$ UTR region comprising $391 \mathrm{bp}$ and cloned downstream of the constitutive 35S promoter into the pTdT-DC-RNAi vector, which co-expresses the tandem dimer tomato (TdT) fluorescent marker that is harboured in the pTdT-DC-RNAi vector. The empty pTdT-DC-RNAi vector was used as the control vector. Next, the PvBPS1-RNAi construct was expressed in Phaseolus by A. rhizogenes-induced hairy roots. Quantitative RT-PCR analysis of the transgenic PvBPS1-RNAi roots showed that the transcript levels of both PvBPS1.1 and PvBPS1.2 were significantly reduced by $\sim 71 \%$ (each) with respect to the transgenic roots of the vector control (Figure 3). These results show that the PvBPS1-RNAi machinery was co-silenced by targeting both the transcripts of PvBPS1.1 and PvBPS1.2. Therefore, the nomenclature PvBPS1, which refers to both PvBPS1.1 and PvBPS1.2, is used henceforth in the manuscript. 

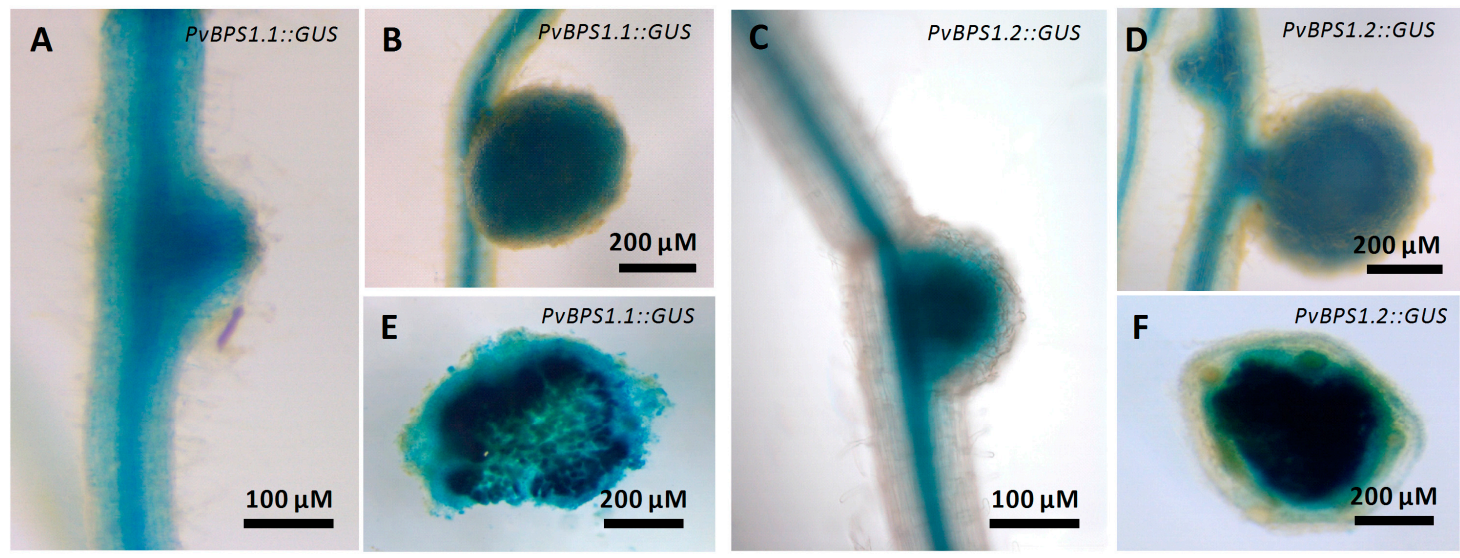

Figure 2. Expression studies of PvBPS1 promoters with $\beta$-glucuronidase reporter in transgenic P. vulgaris nodules. Spatial-temporal pattern of PvBPS1 expression revealed by a promoter: $\beta$-glucuronidase (GUS) construct in nodulated transgenic hairy roots after GUS assay. PvBPS1.1 (Phvul.008G059500) expression in (A) nodule primordium at seven days post inoculation (dpi) and (B) mature nodules at 18 dpi. PvBPS1.2 (Phvul.008G059600) expression in (C) nodule primordium at $7 \mathrm{dpi}$ and (D) mature nodules at $18 \mathrm{dpi}$. Representative images of nodules (18 days old), (E) free hand sections of PvBPS1.1 and (F) PvBPS1.2.

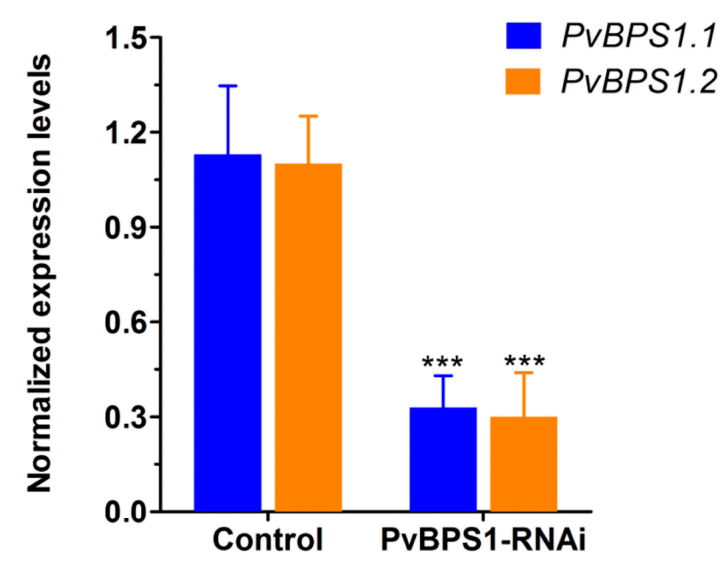

Figure 3. Knockdown of PvBPS1 genes in P. vulgaris transgenic hairy roots. Bean transgenic hairy roots expressing the PvBPS1-RNAi construct were analysed by quantitative reverse transcription PCR (RT-qPCR) at 10 days post emergence (dpe) to measure the transcript abundance of the two PvBPS1 genes viz., PvBPS1.1 and PvBPS1.2. Transcript accumulation was normalized to the expression of the $E f 1 \alpha$ and IDE reference genes. RT-qPCR data are the averages of three biological replicates $(n>9)$. The statistical significance of differences between vector control and interference RNA (RNAi) root samples was determined using an unpaired two-tailed Student's $t$-test $\left.{ }^{* * *} p<0.001\right)$. Error bars represent the means \pm standard error of the mean (SEM).

As seen in previous studies in Arabidopsis, single (BPS1), double (BPS1, BPS2), and triple (BPS1, BPS2, BPS3) mutants were defective in both root and shoot growth at different intensities [23,24]. Here, to investigate whether the BPS1 signal affects root and shoot development in Phaseolus, we first generated composite plants with hairy roots expressing the PvBPS1-RNAi vector. Transgenic roots were carefully selected based on the expression of red fluorescent protein TdT encoded by the vector (Figure S5A-D). Non-fluorescent roots were cut and removed. Control and PvBPS1-RNAi plants with equal sizes and numbers of roots and trifoliates were chosen for study to rule out ambiguity. All of the growth parameters were observed at 10 days post transplantation. PvBPS1-RNA $i$ lines show a significant decrease in primary root length and lateral root density in comparison with control roots 
(Figure 4A,B). Furthermore, the composite plants of PvBPS1-RNAi produced shoots with less biomass and reduced total leaf area when compared to their control counterparts (Figure 4C,D). This suggests that knockdown of PvBPS1 significantly reduces both root and shoot growth in Phaseolus.

A

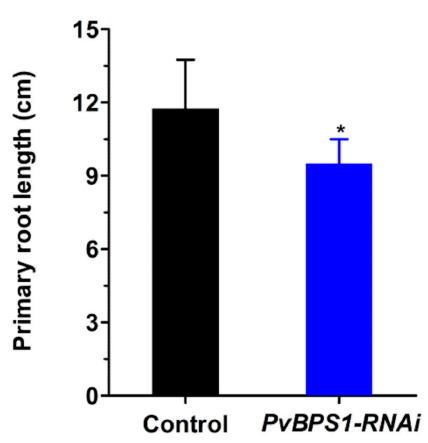

C

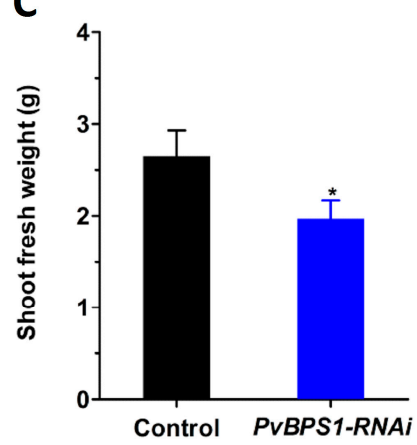

B

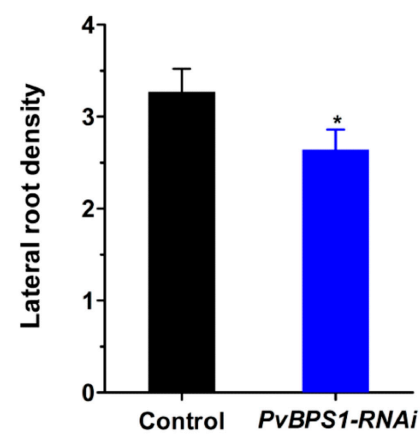

D

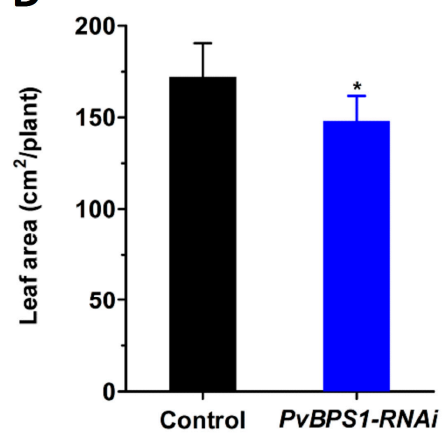

Figure 4. Growth parameters of PvBPS1-RNAi composite plants. The P. vulgaris composite plants containing transgenic hairy roots were analysed after 10 days post transplantation. (A) Primary root length; (B) lateral root density in control and PvBPS1-RNAi roots; (C) Shoot fresh weight and (D) total leaf area of composite plants. The data are the averages of three biological replicates $(n>18)$. The statistical significance of differences between control and RNAi root samples was determined using an unpaired two-tailed Student's $t$-test $\left({ }^{*} p<0.05\right)$. Error bars represent the means $\pm S E M$.

\subsection{Symbiotic Phenotype in PvBPS1-RNAi Plants}

Prior to analysing the symbiotic phenotype, the PvBPS1-RNAi transgenic hairy roots were examined for any morphological alterations in root hairs. The PvBPS1-RNAi roots show no differences in number, length, or position of the root hair cells when compared to control plants that were transformed with pTdT-RNAi empty vector (Figure S6A,B). Next, the PvBPS1-RNAi and control lines were inoculated with $R$. tropici expressing GUS reporter to visualize bacterial growth [43]. At $48 \mathrm{~h}$ post inoculation, the root hair cells of PvBPS1 silenced roots show rhizobia-induced root hair deformations that were similar to those seen in the root hair cells of controls (Figure S6C,D). Interestingly, at 3 dpi, the PvBPS1-RNAi root hair cells show typical root hair curling; an infection pocket filled with rhizobia bacteria and ITs was observed within the root hair curl. However, these ITs were not associated with cortical cell divisions and were aborted at the base of the root hair cell (Figure 5B), whereas the control hairy roots displayed normal kinetics, including several cell layers of dividing cortical cells that harboured branched ITs (Figure 5A). The PvBPS1-RNA $i$ transgenic roots were observed periodically at 3, 5, and $7 \mathrm{dpi}$, and the aborted IT phenotype persisted at all of the observed time points (Figure 5C). Moreover, these roots were devoid of nodule primordia when compared to the control lines (Figure 5D). The absence of nodule formation was repeatedly observed in PvBPS1-RNAi hairy roots of composite plants that were obtained from independent transformation experiments. The transcripts of early nodulin genes, such as ERN1, NIN, and ENOD40 showed curious patterns. While ERN1 expression was 
not affected in PvBPS1 silenced roots at $3 \mathrm{dpi}$, NIN and ENOD40 expression levels were significantly reduced when compared to control roots (Figure 5E). Taken together, the initial signals between the host and Rhizobium were not affected by the silencing of PvBPS1 genes. However, the PvBPS1 genes are required for the Rhizobium infection-associated cortical cell divisions and nodule primordia formation.
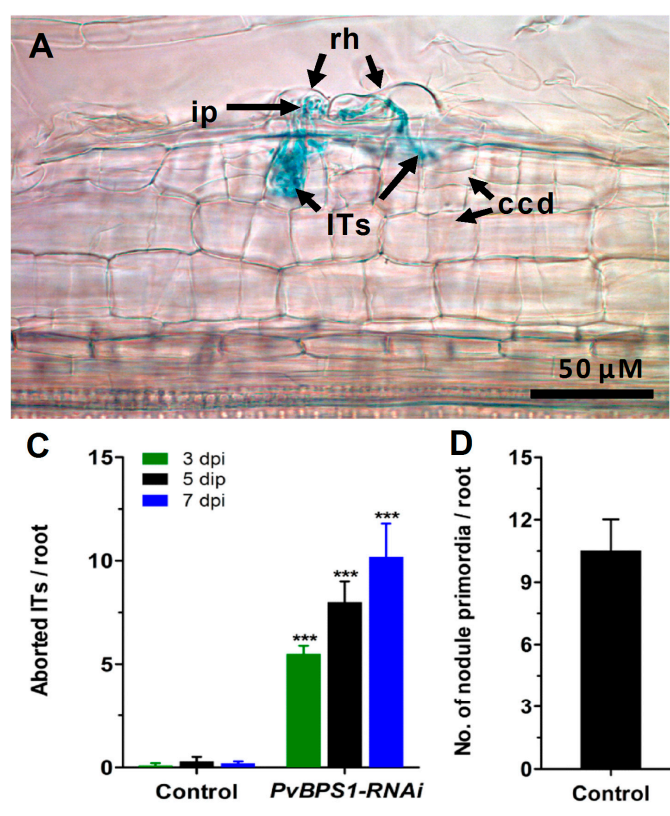

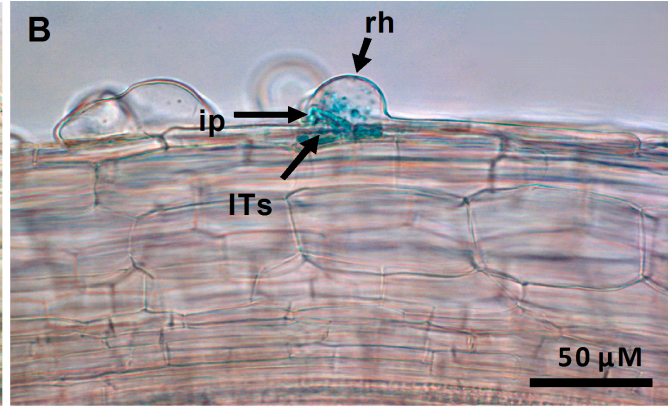

E

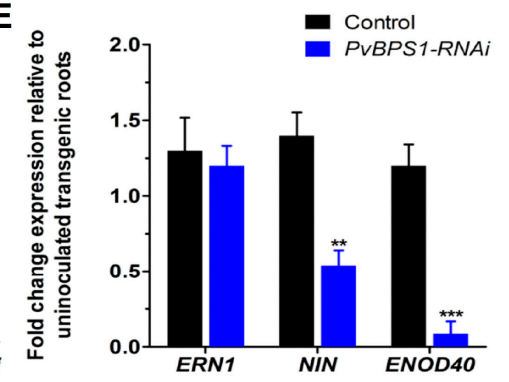

Figure 5. Analysis of phenotype, infection events, and expression profile of early nodulin genes. Phaseolus transgenic hairy roots were inoculated with $R$. tropici expressing a $\beta$-glucuronidase (GUS) reporter and were stained for GUS at different time points and observed using a light microscope. Representative images showing Its in transgenic roots of (A) control and (B) PvBPS1-RNAi at 3 dpi. Quantitative data showing the average number of (C) aborted ITs and (D) nodule primordia per transgenic root. (E) Quantitative RT-PCR analysis showing the transcript levels of nodulin genes viz., ERN1, NIN and ENOD40 in R. tropici-inoculated PvBPS1-RNAi roots at 3 dpi. Transcript accumulation was normalized to the expression of the $E f 1 \alpha$ and IDE reference genes. RT-qPCR data are the averages of three biological replicates $(n>9)$. The statistical significance of differences between control and RNAi root samples was determined using an unpaired two-tailed Student's $t$-test $\left(* * p<0.01 ;{ }^{* * *} p<0.001\right)$. Error bars represent the means \pm SEM. rh, root hair; ip, infection pocket; ITs, infection threads; ccd, cortical cell divisions.

\subsection{Rescue of the Symbiosis Phenotype with Fluridone}

Previous studies in Arabidopsis have shown that the synthesis of BYPASS1, a plant-specific protein that negatively regulates the production of a root-derived mobile BPS1, is known to require an intact $\beta$-carotenoid biosynthesis pathway [23]. The seedlings of BPS1 mutants constitutively produced a signal that resulted in a failure to properly establish pro-vascular tissue, the shoot, and the root meristems [22]. The shoot and root phenotype was recovered in BPS1 mutants when the seedlings were treated with inhibitors of carotenoid biosynthesis pathway [25]. Here, the carotenoid biosynthesis pathway in PvBPS1-silenced Phaseolus plants were inhibited using 1-methyl-2-phenyl-5-[3-(trifluoromethyl)phenyl]-4[1H]-pyridinone (fluridone). First, the roots of wild-type Phaseolus plants were irrigated with different concentrations of fluridone $(0,5,10,50,100$, and $200 \mu \mathrm{M}$ ) to inhibit carotenoid biosynthesis, which resulted in photobleaching and the eventual death of the plants. As depicted in Figure S7A,B, the $100 \mu \mathrm{M}$ concentration of fluridone led to $0 \%$ plant survival (100\% plant mortality) on the 10th day. Next, the same concentration of fluridone was used to treat the PvBPS1-RNAi hairy roots that were inoculated with $R$. tropici in order to examine the recovery of the symbiosis phenotype. Typical nodule primordia were formed in the control roots inoculated with 
either Rhizobium (absolute control; Figure S8) alone or Rhizobium plus fluridone treatment (Figure 6B). Interestingly, the fluridone-treated PvBPS1-RNAi roots show IT progression beyond the root hair cells into the dividing cortical cells (Figure 6C). These rescued ITs and nodule primordial structures were similar to those that were found in controls (Figure 6A,B). Furthermore, the quantitative analysis shows that the average number of ITs that are associated with cortical cells was 5.7 per root in PvBPS1 silenced lines when compared to 11.3 in controls (Figure 6D). Similarly, at least two nodule primordia per root were found in PvBPS1 silenced lines, as compared to 10 in controls (Figure 6E). However, as expected, neither infection events were associated with cortical cell divisions, nor nodule primordia were found in pvBPS1-RNAi roots inoculated with rhizobia alone (Figure 6D,E).
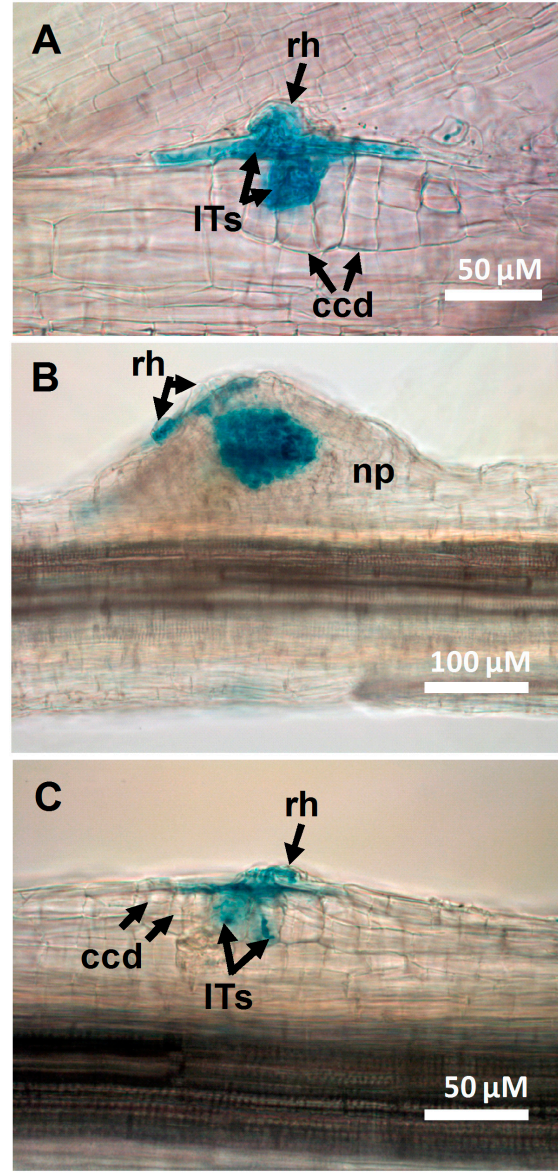
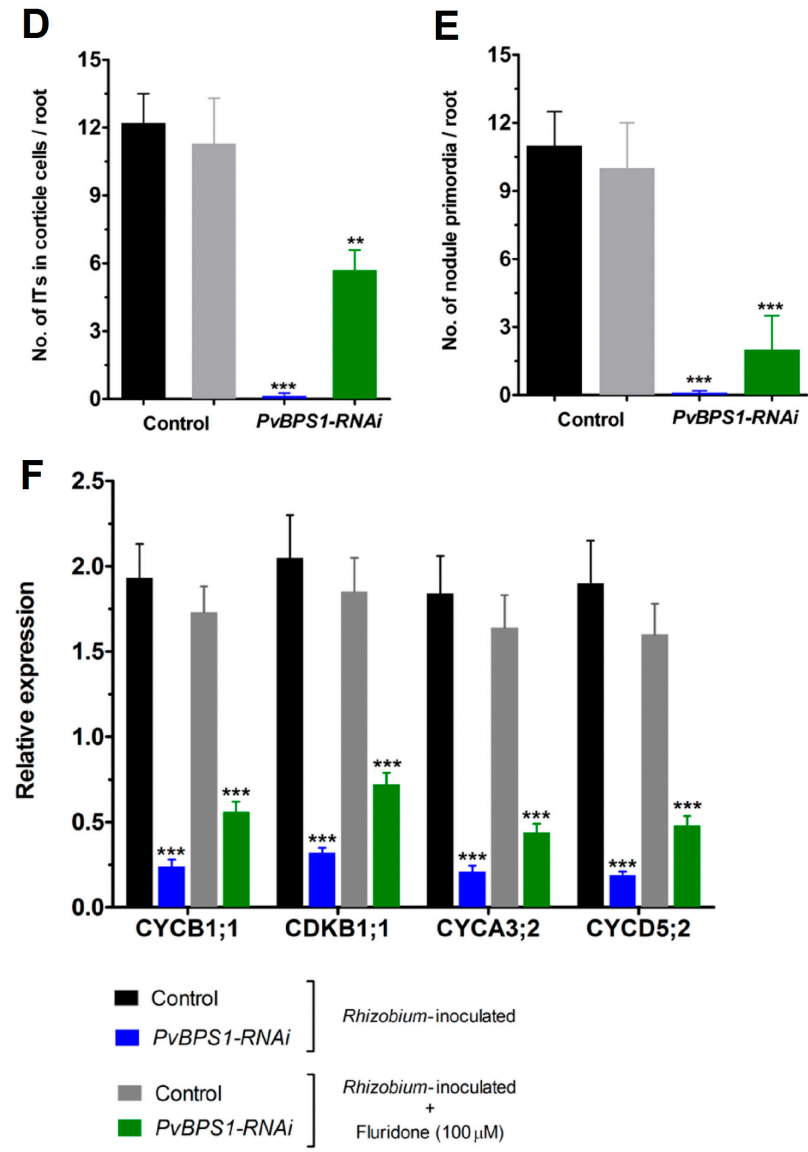

Figure 6. Nodule phenotype rescue by fluridone in PvBPS1-silenced roots. Fluridone (100 uM)-treated Phaseolus transgenic hairy roots were inoculated with $R$. tropici expressing a GUS reporter and were stained for GUS at different time points and observed using a light microscope. Representative images of transgenic roots showing ITs and ccds in control (A), nodule primordia formation in (B) control and (C) PvBPS1-RNAi at 7 dpi. Quantitative data showing the average number of (D) ITs found in dividing cortical cells and (E) nodule primordia per transgenic root. (F) Quantitative RT-PCR analysis of cell cyclins and cyclin-dependent kinase genes in PvBPS1-silenced roots under $R$. tropici-inoculated or $R$. tropici plus fluridone-treated conditions. Transcript accumulation was normalized to the expression of the Ef1 $\alpha$ and IDE reference genes. RT-qPCR data are the averages of three biological replicates $(n>9)$. The statistical significance of differences between control and RNAi root samples was determined using an unpaired two-tailed Student's $t$-test $\left({ }^{* *} p<0.01\right.$; $\left.{ }^{* * *} p<0.001\right)$. Error bars represent the means \pm SEM. Bar colour description: black—Rhizobium inoculated control, grey-Rhizobium inoculated + fluridone treated control, blue—Rhizobium inoculated PvBPS1-RNAi, green-Rhizobium inoculated + fluridone treated PvBPS1-RNAi. rh, root hair; np, nodule primordia; ITs, infection threads; ccd, cortical cell divisions. 
Since fluridone partially rescued rhizobia-induced cortical cell divisions and nodule primordia formation in PvBPS1 silenced roots, we next measured the transcript accumulation of cell cyclins and cyclin-dependent kinases using RT-qPCR. Under rhizobia inoculated conditions, the transcripts of CYCB1;1, CYCA3;2, CYCD5;2, and CDKB1;1 were significantly reduced in PvBPS1-silenced roots with respect to their controls (Figure 6E). Interestingly, when rhizobia-inoculated PvBPS1 silenced roots were treated with fluridone, the transcript levels of CYCB1;1, CYCA3;2, CYCD5;2, and CDKB1;1 increased approximately one-fold when compared to the PvBPS1 silenced roots inoculated with rhizobia alone (Figure 6E). Taken together, our results show that the inhibition of carotenoid biosynthesis in the PvBPS1-silenced roots rescues the nodule phenotype, partially in Phaseolus.

\section{Discussion}

Arabidopsis BPS1 mutations led to the accumulation of a mobile signal molecule, BPS1, which resulted in severe shoot and root growth defects [22-25]. The carotenoid biosynthesis pathway is known to be the source of a BPS signal that regulates shoot and root meristems through cell cycle arrest at the $G_{1}$ phase [26]. Apart from shoot and root meristem, there is a short-lived meristem activity during the nodule organogenesis of legumes that produce determinate type nodules.

There are several hypotheses proposing that the nodule developmental program is derived from the lateral root development program [44-50]. Therefore, similar factors could regulate both root and nodule meristems. Among various factors that regulate plant meristems, long-distance signalling molecules, such as plant hormones, are crucial. During plant organogenesis, the balance of long-distance signalling molecules, auxin and cytokinin signalling is critical for generating secondary organs and maintaining the meristematic activity of plant meristems [51].

The recently identified root-derived long-distance signalling molecule SLs is also found to regulate both shoot growth and root nodule development. In the same context, our findings suggest that the BPS signal is a new candidate that plays a critical role in root nodule symbiosis.

\subsection{BPS1 is Conserved in Legumes}

While identifying BPS1 homologues, a varying number of BPS1 genes were encountered in the selected legume species. Phylogenetic analysis showed that the Phaseolus and Glycine were under one group, irrespective of the conserved motifs in each of these homologues and that the Arabidopsis BPS gene family was in the third group with one Medicago and two G. max homologues. High bootstrap values between Medicago (Medtr8g028710.3) and three homologues of G. max (Glyma.07G066500.1, Glyma.18G129300.1, and Glyma.10G104200.1) show that they could be paralogues. Peptide motifs play important roles in protein networks. In proteins, domain rearrangements and sequence differentiation are essential for new protein functions [52]. The motif analysis of BPS1 proteins showed that motif distributions were not stable in observed legume species. These differences in motif structures prove that gene rearrangements play a critical role in the BPS1 domain organization of BPS1 proteins, the implications of which need to be investigated.

\subsection{Ubiquitous Effect of PvBPS1 Silencing in Phaseolus}

PvBPS1 transcripts were detected in all the tested vegetative and reproductive tissues of Phaseolus. In Arabidopsis, the lack of BPS1 expression leads to the constitutive accumulation of a graft-transmissible signal, which results in developmental defects in shoots and roots [23]. Here, in composite plants of Phaseolus, the hairy roots expressing the PvBPS1-RNA $i$ vector showed reductions in primary root length and LR density. At the same time, the untransformed shoot apices also showed developmental defects, such as growing smaller leaves and a reduction in shoot biomass. The shoot phenotype in the present experiment demonstrates once again that the BPS1 signal is root-derived.

Curiously, PvBPS1 gene transcripts (PvBPS1.1 and PvBPS1.2) were detected at all of the developmental stages of root nodule development. Specifically, high expression was documented three and five days post inoculation with Rhizobium. Furthermore, the promoter expression pattern of the 
PvBPS1 genes was found within the central tissues of nodules, which coincides with high transcript accumulation. These data indicate a possible functional role of PvBPS1 during rhizobial symbiosis in Phaseolus.

\subsection{PvBPS1 Signal Suppresses Cortical Cell Divisions during Root Nodule Symbiosis}

Previous reports revealed that a BPS1 signal was a novel developmental signal that functions during embryogenesis and vegetative growth [27]. In the current study, PvBPS1 silencing in Phaseolus resulted in developmental defects in root and shoot tissues. Unlike Arabidopsis, the root hair morphology did not change in Phaseolus, and when these roots were inoculated with Rhizobium, normal infection threads grew, which were aborted at the base of root hair cell. However, cortical cell divisions were absent in PvBPS1-RNAi plants, indicating that in the absence of the PvBPS1 transcript, the BPS1 signal accumulates and affects the meristematic activity in the root cortex. The transcripts of early nodulin genes support the observation that early host-Rhizobium signalling is not affected. Furthermore, the reduction in transcript accumulation of $\mathrm{G}_{2} / \mathrm{M}$ phase cyclins and CDKs implies cell cycle arrest resulting in the absence of cortical cell divisions.

Furthermore, the partial recovery of the symbiotic phenotype upon treatment with carotenoid biosynthesis pathway inhibitors proves that nodule meristem development is affected by the BPS1 signal, similar to root and shoot meristems. Nodules are often thought to share some developmental programs with lateral roots. Recent studies confirmed the expression of orthologues of a number of known Arabidopsis root meristem regulators in the nodule, among them MtWOX5, MtPLT2, and MtBBM/PLT4 [53-55]. Taken together, these data suggest that the BPS1 signal could affect all meristem types in plants, including rhizobia-induced cortical cell divisions.

Supplementary Materials: The following are available online at www.mdpi.com/2073-4425/9/1/11/s1, Figure S1: Multiple sequence alignment of BPS1 proteins; Figure S2: Domain structure of BPS1 homologues; Figure S3: Gene structures of BPS homologues; Figure S4: Motif patterns and WebLogo plots of BPS homologues; Figure S5: Transgenic hairy roots expressing red fluorescence in Phaseolus; Figure S6: Phaseolus transgenic hairy roots showing root hair morphology; Figure S7: Fluridone dose-response curve (survival) in wild-type P. vulgaris plants; Figure S8: Young nodule on transgenic control root. Table S1: Primer sequences of Phaseolus vulgaris genes used for cloning and RT-qPCR; Table S2: Percent amino acid sequence identity of BPS1 genes.

Acknowledgments: We thank Alma-Leticia Aguirre and Brenda-Mariana Gómez, undergraduate students, Ciencias Agrogenómicas, Escuela Nacional de Estudios Superiores Unidad León, Universidad Nacional Autónoma de México (UNAM) for assisting in cloning of PvBPS1-RNAi construct. This work was partially supported by the Dirección General de Asuntos del Personal Académico, DGAPA/PAPIIT-UNAM grant no. IA205117 to M.-K.A. and IN219916 to M.L.

Author Contributions: M.-K.A. designed the experiments and contributed to the production of the vector constructs and microscopy. K.N. drafted the manuscript, RT-qPCR analysis, and bioinformatics analyses and contributed to the experimental design. M.L. coordinated the study and finalized the article.

Conflicts of Interest: The authors declare no conflict of interest.

\section{References}

1. DellaPenna, D.; Pogson, B.J. Vitamin synthesis in plants: Tocopherols and carotenoids. Annu. Rev. Plant Biol. 2006, 57, 711-738. [CrossRef] [PubMed]

2. Lu, S.; Li, L. Carotenoid metabolism: Biosynthesis, regulation, and beyond. J. Integr. Plant Biol. 2008, 50, 778-785. [CrossRef] [PubMed]

3. Demmig-Adams, B.; Adams, W.W. Photoprotection and other responses of plants to high light stress. Annu. Rev. Plant Mol. Biol. 1992, 43, 599-626. [CrossRef]

4. Demmig-Adams, B.; Adams, W.W. Antioxidants in photosynthesis and human nutrition. Science 2002, 298, 249-253. [CrossRef] [PubMed]

5. Niyogi, K.K.; Bjorkman, O.; Grossman, A.R. The roles of specific xanthophylls in photoprotection. Proc. Natl. Acad. Sci. USA 1997, 94, 14162-14167. [CrossRef] [PubMed]

6. Auldridge, M.E.; Block, A.; Vogel, J.T.; Dabney-Smith, C.; Mila, I.; Bouzayen, M.; Magallanes-Lundback, M.; DellaPenna, D.; McC-arty, D.R.; Klee, H.J. Characterization of three members of the Arabidopsis carotenoid 
cleavage dioxygenase family demonstrates the divergent roles of this multifunctional enzyme family. Plant $J$. 2006, 45, 982-993. [CrossRef] [PubMed]

7. Strack, D.; Fester, T. Isoprenoid metabolism and plastid reorganization in arbuscular mycorrhizal roots. New Phytol. 2006, 172, 22-34. [CrossRef] [PubMed]

8. Tsuchiya, Y.; McCourt, P. Strigolactones: A new hormone with a past. Curr. Opin. Plant Biol. 2009, 12, 556-561. [CrossRef] [PubMed]

9. Walter, M.H.; Floss, D.S.; Strack, D. Apocarotenoids: Hormones, mycorrhizal metabolites and aroma volatiles. Planta 2010, 232, 1-17. [CrossRef] [PubMed]

10. Furutani, M.; Vernoux, T.; Traas, J.; Kato, T.; Tasaka, M.; Aida, M. PIN-FORMED1 and PINOID regulate boundary formation and cotyledon development in Arabidopsis embryogenesis. Development 2004, 131, 5021-5030. [CrossRef] [PubMed]

11. Blilou, I.; Xu, J.; Wildwater, M.; Willemsen, V.; Paponov, I.; Friml, J.; Heidstra, R.; Aida, M.; Palme, K.; Scheres, B. The PIN auxin efflux facilitator network controls growth and patterning in Arabidopsis roots. Nature 2005, 433, 39-44. [CrossRef] [PubMed]

12. Galinha, C.; Hofhuis, H.; Luijten, M.; Willemsen, V.; Blilou, I.; Heidstra, R.; Scheres, B. PLETHORA proteins as dose-dependent master regulators of Arabidopsis root development. Nature 2007, 449, 1053-1057. [CrossRef] [PubMed]

13. Dubrovsky, J.G.; Sauer, M.; Napsucialy-Mendivil, S.; Ivanchenko, M.G.; Friml, J.; Shishkova, S.; Celenza, J.; Benková, E. Auxin acts as a local morphogenetic trigger to specify lateral root founder cells. Proc. Natl. Acad. Sci. USA 2008, 105, 8790-8794. [CrossRef] [PubMed]

14. Gomez-Roldan, V.; Fermas, S.; Brewer, P.B.; Puech-Pagès, V.; Dun, E.A.; Pillot, J.P.; Letisse, F.; Matusova, R.; Danoun, S.; Portais, J.C.; et al. Strigolactone inhibition of shoot branching. Nature 2008, 455, 189-194. [CrossRef] [PubMed]

15. Umehara, M.; Hanada, A.; Yoshida, S.; Akiyama, K.; Arite, T.; Takeda-Kamiya, N.; Magome, H.; Kamiya, Y.; Shirasu, K.; Yoneyama, K.; et al. Inhibition of shoot branching by new terpenoid plant hormones. Nature 2008, 455, 195-200. [CrossRef] [PubMed]

16. Vogel, J.T.; Walter, M.H.; Giavalisco, P.; Lytovchenko, A.; Kohlen, W.; Charnikhova, T.; Simkin, A.J.; Goulet, C.; Strack, D.; Bouwmeester, H.J.; et al. SICCD7 controls strigolactone biosynthesis, shoot branching and mycorrhiza-induced apocarotenoid formation in tomato. Plant J. 2010, 61, 300-311. [CrossRef] [PubMed]

17. Ruyter-Spira, C.; Al-Babili, S.; van der Krol, S.; Bouwmeester, H. The biology of strigolactones. Trends Plant Sci. 2013, 18, 72-83. [CrossRef] [PubMed]

18. Soto, M.J.; Fernández-Aparicio, M.; Castellanos-Morales, V.; García-Garrido, J.M.; Ocampo, J.A.; Delgado, M.J.; Vierheilig, H. First indications for the involvement of strigolactones on nodule formation in alfalfa (Medicago sativa). Soil Biol. Biochem. 2010, 42, 383-385. [CrossRef]

19. Foo, E.; Davies, N.W. Strigolactones promote nodulation in pea. Planta 2011, 234, 1073-1081. [CrossRef] [PubMed]

20. Foo, E.; Yoneyama, K.; Hugill, C.; Quittenden, L.; Reid, J. Strigolactones and the regulation of pea symbioses in response to nitrate and phosphate deficiency. Mol. Plant 2013, 6, 76-87. [CrossRef] [PubMed]

21. Liu, J.; Novero, M.; Charnikhova, T.; Ferrandino, A.; Schubert, A.; Ruyter Spira, C.; Bonfante, P.; Lovisolo, C.; Bouwmeester, H.J.; Cardinale, F. Carotenoid cleavage dioxygenase 7 modulates plant growth, reproduction, senescence, and determinate nodulation in the model legume Lotus japonicus. J. Exp. Bot. 2013, 64, 1967-1981. [CrossRef] [PubMed]

22. Lee, D.K.; Van Norman, J.M.; Murphy, C.; Adhikari, E.; Reed, J.W.; Sieburth, L.E. In the absence of BYPASS1-related gene function, the bps signal disrupts embryogenesis by an auxin-independent mechanism. Development 2012, 139, 805-815. [CrossRef] [PubMed]

23. Van Norman, J.M.; Frederick, R.L.; Sieburth, L.E. BYPASS1 negatively regulates a root-derived signal that controls plant architecture. Curr. Biol. 2004, 14, 1739-1746. [CrossRef] [PubMed]

24. Van Norman, J.M.; Murphy, C.; Sieburth, L.E. BYPASS1: Synthesis of the mobile root-derived signal requires active root growth and arrests early leaf development. BMC Plant Biol. 2011, 11, 28. [CrossRef] [PubMed]

25. Van Norman, J.M.; Sieburth, L.E. Dissecting the biosynthetic pathway for the bypass1 root-derived signal. Plant J. 2007, 49, 619-628. [CrossRef] [PubMed]

26. Adhikari, E.; Lee, D.K.; Giavalisco, P.; Sieburth, L.E. Long-distance signaling in bypass1 mutants: Bioassay development reveals the bps signal to be a metabolite. Mol. Plant 2013, 6, 164-173. [CrossRef] [PubMed] 
27. Tominaga, A.; Nagata, M.; Futsuki, K.; Abe, H.; Uchiumi, T.; Abe, M.; Kucho, K.; Hashiguchi, M.; Akashi, R.; Hirsch, A.; et al. Effect of abscisic acid on symbiotic nitrogen fixation activity in the root nodules of Lotus japonicus. Plant Signal Behav. 2010, 5, 440-443. [CrossRef] [PubMed]

28. Nanjareddy, K.; Arthikala, M.K.; Gómez, B.M.; Blanco, L.; Lara, M. Differentially expressed genes in mycorrhized and nodulated roots of common bean are associated with defense, cell wall architecture, N metabolism, and P metabolism. PLoS ONE 2017, 12, e0182328. [CrossRef] [PubMed]

29. Broughton, W.J.; Dilworth, M.J. Control of leghemoglobin synthesis in snake beans. Biochem. J. 1971, 125, 1075-1080. [CrossRef] [PubMed]

30. Di Tommaso, P.; Moretti, S.; Xenarios, I.; Orobitg, M.; Montanyola, A.; Chang, J.M.; Taly, J.F.; Notredame, C. T-Coffee: A web server for the multiple sequence alignment of protein and RNA sequences using structural information and homology extension. Nucleic Acids Res. 2011, 39, W13-W17. [CrossRef] [PubMed]

31. Timothy, L.; Mikael Bodén, B.; Buske, F.A.; Frith, M.; Grant, C.E.; Clementi, L.; Ren, J.; Li, W.W.; Noble, W.S. MEME SUITE: Tools for motif discovery and searching. Nucleic Acids Res. 2009, 37, 202-208. [CrossRef]

32. Kumar, S.; Stecher, G.; Tamura, K. MEGA7: Molecular evolutionary genetics analysis version 7.0 for bigger datasets. Mol. Biol. Evol. 2016, 33, 1870-1874. [CrossRef] [PubMed]

33. Nanjareddy, K.; Arthikala, M.K.; Aguirre, A.L.; Gómez, B.M.; Lara, M. Plant promoter analysis: Identification and characterization of root nodule specific promoter in common bean. J. Vis. Exp. 2017, 130, e56140. [CrossRef]

34. Karimi, M.; Inze, D.; Depicker, A. Gateway vectors for Agrobacterium-mediated plant transformation. Trends Plant Sci. 2002, 7, 193-195. [CrossRef]

35. Valdeés-López, O.; Arenas-Huertero, C.; Ramírez, M.; Girard, L.; Sánchez, F.; Vance, C.P.; Luis Reyes, J.; Hernández, G. Essential role of MYB transcription factor: PvPHR1 and microRNA: PvmiR399 in phosphorus deficiency signalling in common bean roots. Plant Cell Environ. 2008, 31, 1834-1843. [CrossRef] [PubMed]

36. Shaner, N.C.; Campbell, R.E.; Steinbach, P.A.; Giepmans, B.N.; Palmer, A.E.; Tsien, R.Y. Improved monomeric red, orange and yellow fluorescent proteins derived from Discosoma sp. red fluorescent protein. Nat. Biotechnol. 2004, 22, 1567-1572. [CrossRef] [PubMed]

37. Dubrovsky, J.G.; Gambetta, G.A.; Hernández-Barrera, A.; Shishkova, S.; González, I. Lateral root initiation in Arabidopsis: Developmental window, spatial patterning, density and predictability. Ann. Bot. 2006, 97, 903-915. [CrossRef] [PubMed]

38. Easlon, H.M.; Bloom, A.J. Easy Leaf Area: Automated digital image analysis for rapid and accurate measurement of leaf area. Appl. Plant Sci. 2014, 2. [CrossRef] [PubMed]

39. Bustin, S.A.; Benes, V.; Garson, J.A.; Hellemans, J.; Huggett, J.; Kubista, M.; Mueller, R.; Nolan, T.; Pfaffl, M.W.; Shipley, G.L.; et al. The MIQE guidelines: Minimum information for publication of quantitative real-time PCR experiments. Clin. Chem. 2009, 55, 611-622. [CrossRef] [PubMed]

40. Arthikala, M.K.; Montiel, J.; Nava, N.; Santana, O.; Sánchez-López, R.; Cárdenas, L.; Quinto, C. PvRbohB negatively regulates Rhizophagus irregularis colonization in Phaseolus vulgaris. Plant Cell Physiol. 2013, 54, 1391-1402. [CrossRef] [PubMed]

41. Vandesompele, J.; De Preter, K.; Pattyn, F.; Poppe, B.; Van-Roy, N.; De Paepe, A.; Speleman, F. Accurate normalization of real-time quantitative RT-PCR data by geometric averaging of multiple internal reference genes. Genome Biol. 2002, 3. [CrossRef]

42. Jefferson, R.A. Assaying chimeric genes in plants, the GUS gene fusion system. Plant Mol. Biol. Rep. 1987, 5, 387-405. [CrossRef]

43. Vinuesa, P.; Neumann-Silkow, F.; Pacios-Bras, C.; Spaink, H.P.; Martínez-Romero, E.; Werner, D. Genetic analysis of a pH-regulated operon from Rhizobium tropici CIAT899 involved in acid tolerance and nodulation competitiveness. Mol. Plant Microbe Interact. 2003, 16, 159-168. [CrossRef] [PubMed]

44. Nutman, P.S. Physiological studies on nodule formation. 1. The relation between nodulation and lateral root formation in red clover. Ann. Bot. 1948, 12, 81-96. [CrossRef]

45. Hirsch, A.M.; Larue, T.A.; Doyle, J. Is the legume nodule a modified root or stem or an organ sui generis? Crit. Rev. Plant Sci. 1997, 16, 361-392. [CrossRef]

46. Mathesius, U.; Weinman, J.J.; Rolfe, B.G.; Djordjevic, M.A. Rhizobia can induce nodules in white clover by "hijacking" mature cortical cells activated during lateral root development. Mol. Plant Microbe Interact. 2000, 13, 170-182. [CrossRef] [PubMed] 
47. De Billy, F.; Grosjean, C.; May, S.; Bennett, M.; Cullimore, J.V. Expression studies on AUX1-like genes in Medicago truncatula suggest that auxin is required at two steps in early nodule development. Mol. Plant Microbe Interact. 2001, 14, 267-277. [CrossRef] [PubMed]

48. Roudier, F.; Fedorova, E.; Lebris, M.; Lecomte, P.; Györgyey, J.; Vaubert, D.; Horvath, G.; Abad, P.; Kondorosi, A.; Kondorosi, E. The Medicago species A2-type cyclin is auxin regulated and involved in meristem formation but dispensable for endoreduplication-associated developmental programs. Plant Physiol. 2003, 131, 1091-1103. [CrossRef] [PubMed]

49. Bright, L.J.; Liang, Y.; Mitchell, D.M.; Harris, J.M. The LATD gene of Medicago truncatula is required for both nodule and root development. Mol. Plant Microbe Interact. 2005, 18, 521-532. [CrossRef] [PubMed]

50. Desbrosses, G.J.; Stougaard, J. Root nodulation: A paradigm for how plant-microbe symbiosis influences host developmental pathways. Cell Host Microbe 2011, 10, 348-358. [CrossRef] [PubMed]

51. Stahl, Y.; Simon, R. Plant primary meristems: Shared functions and regulatory mechanisms. Curr. Opin. Plant Biol. 2010, 13, 53-58. [CrossRef] [PubMed]

52. Bjorklund, A.K.; Ekman, D.; Light, S.; Frey-Skott, J.; Elofsson, A. Domain rearrangements in protein evolution. J. Mol. Biol. 2005, 353, 911-923. [CrossRef] [PubMed]

53. Osipova, M.A.; Dolgikh, E.A.; Lutova, L.A. Features of the expression of a meristem-specific WOX5 gene during nodule organogenesis in legumes. Ontogenez 2011, 42, 264-275. [PubMed]

54. Osipova, M.A.; Mortier, V.; Demchenko, K.N.; Tsyganov, V.E.; Tikhonovich, I.A.; Lutova, L.A.; Dolgikh, E.A.; Goormachtig, S. WUSCHEL-RELATED HOMEOBOX5 gene expression and interaction of CLE peptides with components of the systemic control add two pieces to the puzzle of autoregulation of nodulation. Plant Physiol. 2012, 158, 1329-1341. [CrossRef] [PubMed]

55. Roux, B.; Rodde, N.; Jardinaud, M.F.; Timmers, T.; Sauviac, L.; Cottret, L.; Carrère, S.; Sallet, E.; Courcelle, E.; Moreau, S.; et al. An integrated analysis of plant and bacterial gene expression in symbiotic root nodules using laser-capture microdissection coupled to RNA sequencing. Plant J. 2014, 77, 817-837. [CrossRef] [PubMed]

(C) 2018 by the authors. Licensee MDPI, Basel, Switzerland. This article is an open access article distributed under the terms and conditions of the Creative Commons Attribution (CC BY) license (http:/ / creativecommons.org/licenses/by/4.0/). 